\title{
Lombe, sebagai upaya konservasi kerbau di Pulau Kangean Kabupaten
} Sumenep

\author{
Misbahul Ulum*, Kartika Hardiyanti", Irfan* \\ * Pendidikan Geografi, Fakultas Ilmu Sosial, Universitas Negeri Malang
}

\begin{tabular}{l}
\hline \hline INFO ARTIKEL \\
\hline Riwayat Artikel: \\
Dikirim: $25-1-2018$ \\
Disetujui: $23-4-2018$ \\
Diterbitkan: $31-1-2019$ \\
\\
\hline Kata kunci: \\
tradisi Lombe; konservasi \\
kerbau; Pulau Kangean
\end{tabular}

\begin{abstract}
ABSTRAK
Abstract: Lombe tradition is a buffalo race tradition from Kangean Island, Sumenep Regency. Lombe Traditions are not owned by other regions in Indonesia. This tradition is still done now by the Kangean people. The conservation of Lombe Tradition is believed to support the efforts of buffalo conservation in Kangean Island. Lombe Tradition needs to be taken into account as an asset of Indonesia's national culture but this tradition is not widely known nationally. The purpose of this study is to describe the Conservation of Lombe as a conservation effort of buffalo in Kangean Island and Lombe tradition impact on social and economic people of Kangean. This research uses qualitative descriptive approach with observation and interview method. Lombe Tradition became an effort to preserve the buffalo on Kangean Island. Lombe Traditions can have social impacts such as strengthening social ties and strengthening the ropes of Kangean people, economic impacts This tradition is increasing the value of buffalo selling prices and maintaining and increasing buffalo population thus affecting the number of buffalo shipments to various regions in Indonesia hence, by itself the economic level of people are increasing.
\end{abstract}

Abstrak: Tradisi Lombe merupakan tradisi kerapan kerbau dari Pulau Kangean, Kabupaten Sumenep. Tradisi Lombe tidak dimiliki oleh daerah lain di Indonesia. Tradisi ini masih dilakukan hingga sekarang oleh masyarakat Kangean. Kelestarian Tradisi Lombe diduga mendukung upaya konservasi kerbau di Pulau Kangean. Tradisi Lombe perlu diperhitungkan sebagai aset kebudayaan nasional Indonesia tetapi tradisi ini tidak banyak diketahui keberadaanya secara nasional. Tujuan penelitian ini adalah mendeskripsikan Pelestarian Tradisi Lombe sebagai upaya konservasi kerbau di Pulau Kangean dan dampak Tradisi Lombe terhadap sosial dan ekonomi masyarakat Kangean. Penelitian ini menggunakan pendekatan deskriptif kualitatif dengan metode observasi dan wawancara.Tradisi Lombe menjadi upaya untuk menjaga kelestarian kerbau di Pulau Kangean. Tradisi Lombe dapat memberikan dampak sosial seperti meperkuatt ikatan sosial dan mempererat tali persaudaraan masyarakat Kangean, dampak ekonomi Tradisi ini adalah meningkatkan nilai harga jual kerbau serta mempertahankan dan meningkatkan populasi kerbau dengan demikian mempengaruhi jumlah pengiriman kerbau ke berbagai daerah di Indonesia maka, dengan sendirinya taraf perekonomian rakyat meningkat. 
Jurnal Pendidikan Geografi:

Kajian, Teori, dan Praktik dalam Bidang Pendidikan dan Ilmu Geografi

Tahun 24, Nomor 1, Jan 2019, Hal 1-10

\author{
Alamat Korespondensi: \\ Misbahul Ulum \\ Pendidikan Geografi \\ Universitas Negeri Malang \\ Jalan Semarang No. 5 Malang \\ E-mail: misbahululum1702@gmail.com
}

\title{
PENDAHULUAN
}

Kebudayaan sebagai aktivitas manusia yang melibatkan unsur karsa, rasa dan cipta ibarat lingkaran yang tidak mengenal ujung ataupun pangkalnya. Warner dan Joynt (2002:3) mengatakan Budaya (culture) merupakan identitas yang dimiliki suatu kelompok manusia dalam bermasyarakat. Kata culture ini diadaptasi dari bahasa Latin, yaitu "cult" yang berarti mendiami, mengerjakan, atau memuja, dan "are" yang berarti hasil dari sesuatu. Mempertahankan, memelihara, mengembangkan serta menyempurnakan budaya dan tradisi merupakan kewajiban masyarakat baik dalam arti perorangan, kelompok maupun dalam arti keseluruhan. Ciri khas dan kepribadian suatu bangsa terutama terletak pada tradisi yang dimilikinya. Indonesia adalah negara yang memiliki kebudayaan beranekaragam disetiap daerah. Kebudayaan tersebut terbentang dari Sabang sampai Merauke salah satunya Pulau Kangean yang terletak di ujung timur Pulau Madura yang memiliki tradisi yang unik dan berbeda yaitu Tradisi Lombe atau Kerapan Kerbau.

Menurut Sahwanoedin (2005) Kangeanmerupakan salah satu pulau dari Kepulauan Kangean yang memiliki luas $430 \mathrm{~km} 2$, dan titik tertingginya mencapai 390 meter dpl. Secara administratif pulau ini berada di wilayah Kabupaten Sumenep, Provinsi Jawa Timur, Indonesia. Masyarakat Pulau Kangean mayoritas bermata pencaharian petani. Sejak tahun 1960-an Masyarakat petani Kangean memiliki inisiatif melaksanakan kerapan kerbau yang mereka sebut pada perkembangannya Tradisi Lombe, Lombe menurut masyarakat Kangean pada dasarnya bukan sekedar suatu pertunjukan lomba atau kerapan semata, konon dibalik itu terdapat nilai ritual sebagai bentuk usaha masyarakat setempat sebagai bentuk permohonan kepada Yang Maha Kuasa agar dilimpahkan rezeki ketika menghadapi panen padi.

Tradisi Lombe merupakan salah satu budaya yang masih terjaga dan berkembang hingga saat ini di Pulau Kangean. Ketersedian kerbau untuk tradisi tersebut diduga mendukung konservasi kerbau khususnya di daerah Madura dan Jawa Timur. Penelitian yang mengkaji Tradisi Lombe ini merupakan yang pertama. Tujuan penelitian ini yaitu mendiskripsikan: Tradisi Lombe di Pulau Kangean, fungsi Tradisi Lombe sebagai konservasi kerbau di Pulau Kangean, dan dampak sosial ekonomi Tradisi Lombe terhadap masyarakat Pulau Kangean. Manfaat dan potensi penelitian ini mendukung kelestarian Tradisi Lombe di Pulau Kangean, memperkenalkan Tradisi Lombe di tingkat nasional sehingga potensi Kangean sebagai pulau wisata budaya dan menjadi ikon budaya Indonesia di tingkat Internasional, bersama dengan hal tersebut konservasi kerbau tetap terjaga dan diharapkan meningkatkan perekonomian masyarakat Kangean. 
Jurnal Pendidikan Geografi:

Kajian, Teori, dan Praktik dalam Bidang Pendidikan dan Ilmu Geografi

Tahun 24, Nomor 1, Jan 2019, Hal 1-10

\section{Rancangan Penilitian}

\section{METODE}

Penelitian ini menggunakan metode kualitatif, dengan rancangan penelitian deskriptif kualitatif yaitu penelitian yang mengolah data verbal berupa kata-kata tertulis, perilaku, keyakinan atau lisan dari orang-orang dan pelaku yang diamati.

\section{Objek dan Subjek Penelitian}

Objek dari penelitian ini Tradisi Lombe dan konservasi kerbau. Subjek dari penelitian ini masyarakat Pulau Kangean.

\section{Waktu dan Tempat Penelitian}

Penelitian ini dilaksanakan selama 4 bulan (Mei-Juli). Tempat penelitian di Dusun Gerangmoseng, Desa Angkatan, Pulau Kangean, Kabupaten Sumenep.

\section{Instrumen Penelitian}

Instrumen utama yang digunakan dalam penelitian ini adalah human instrument dan didukung oleh pedoman wawancara dan dokumentasi yang berupa audio visual maupun foto atau gambar.

Pengumpulan Data

Adapun metode pengumpulan data yang digunakan yaitu:

a. Studi literatur. Untuk mendapatakan informasi tentang Tradisi Lombe dan konservasi kerbau dari buku, jurnal, paper, artikel dan sumber lain guna mendapatkan gambaran menyeluruh tentang apa yang diteliti. Tetapi hingga saat ini masih belum ditemukan literatur tentang Tradisi Lombe karena belum pernah ada penelitian tentang tradisi ini. Peneliti hanya melihat dan menganalisis melalui video sehingga dapat dijadikan pembanding sebelum melakukan observasi ke lapangan.

b. Observasi. Observasi dilakukan untuk melihat secara langsung pelaksanaan Tradisi Lombe serta aktifitas masyarakat yang berkaitan dengan tradisi ini. Peneliti juga mendatangi beberapa perternakan kerbau di Desa Bilis bilis dan Desa Laok Jang-jang Kecamatan Arjasa. Perolehan data dan fakta dari pelaksanaan tradisi juga dengan mencermati video tentang tradisi ini, melihat secara langsung dampak sosial ekonomi tradisi terhadap masyarakat.

c. Wawancara. Wawancara dilakukan untuk mendapatkan informasi dari narasumber yang dipilih berdasarkan kebutuhan penelitian dan kapasitas mereka sebagai tokoh masyarakat yang paham tentang Tradisi Lombe. Narasumber berjumlah tujuh orang yaitu masyarakatyang melakukan Tradisi Lombe dan peternak kerbau yang dapat memberikan informasi. Wawancara di lakukan terhadap tokoh masyarakat yang mengerti dan paham tentang Tradisi Lombe, yaitu Bapak Gassing 43 tahun, menjabat sebagai sekretaris Desa Angkatan), Bapak Musahra (62 tahun, sebagai peternak dan pedagang kerbau), Bapak Azmi (34 tahun, petani dan peternak kerbau), Bapak Suhri (67 tahun, sebagai petani dan beternak), Bapak Muksin (86 tahun, petani dan peternak kerbau), Amnawiya (40 tahun, pedagang), serta Ahmad Supriadi (20 tahun, mahasiswa). Wawancara dilakukan untuk mendapatkan data tentang sejarah dan perkembangan Tradisi Lombe, fungsi tradisi untuk konservasi kerbau dan dampak sosial ekonomi tradisi ini terhadap masyarakat.

d. Focus Group Discussion. Metode terakhir ini digunakan untuk mengumpulkan data lewat diskusi terpusat, mengundang beberapa tokoh masyarakat dan mengkaji data yang sudah didapat saat observasi dan wawancara untuk menyempurnakan atau melengkapi data dengan harapan memperoleh hasil pemaknaan yang lebih objektif. 
Jurnal Pendidikan Geografi:

Kajian, Teori, dan Praktik dalam Bidang Pendidikan dan Ilmu Geografi

Tahun 24, Nomor 1, Jan 2019, Hal 1-10

\section{Teknik Analisis Data}

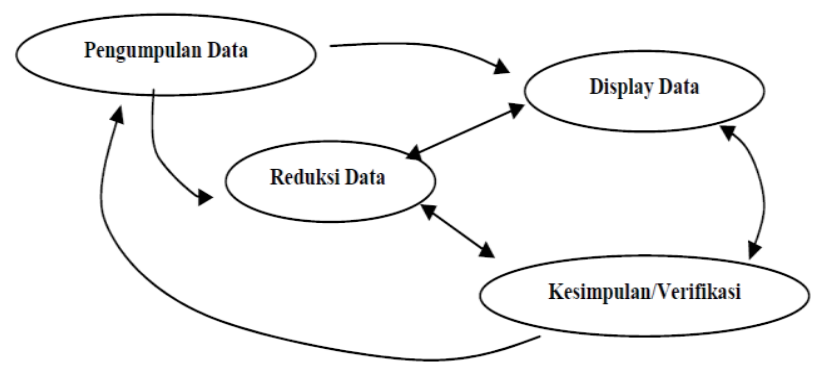

Gambar 1. Kompenen analisis data: Model Interaktif (Sumber: Miles dan Huberman, 1992:20)

Berdasarkan pada Gambar 1, maka wawancara dan observasi telah dilakukan dan dianalisis dengan tahapan sebagai berikut:

1. Pengumpulan Data

Pengumpulan data dilakukan dengan cara observasi dan wawancara. Data yang terkumpul berupa informasi tentang Tradisi Lombe, konservasi kerbau, dampak sosial ekonomi pelaksanaan Tradisi Lombe terhadap masyarkat. Kemudian dilakukan analisis melalui tiga tahapan yaitu reduksi data, penyajian data dan penarikan kesimpulan.

2. Reduksi Data

Tahapan ini dilakukan dengan cara melakukan proses pemilihan, pengklarifikasian, pengabstraksian atau transparansi data yang diperoleh, baik melalui observasi maupun wawancara kepada informan pangkal dan informan kunci.

3. Penyajian Data

Penyajian data terhadap sekumpulan informasi yang tersusun akan memberi kemungkinan adanya penarikan kesimpulan dan mengambil tindakan. Menyajikan data dilakukan untuk memahami apa yang terjadi, merencanakan kerja selanjutnya berdasarkan apa yang telah dipahami.

4. Penarikan kesimpulan

Setelah peneliti memaparkan data dari hasil fakta dilapangan terkait Tradisi Lombe, konservasi kerbau dan dampak sosial ekonomi masyarakat kangean. Peneliti menarik kesimpulan untuk menjawab tujuan dari penelitian ini.

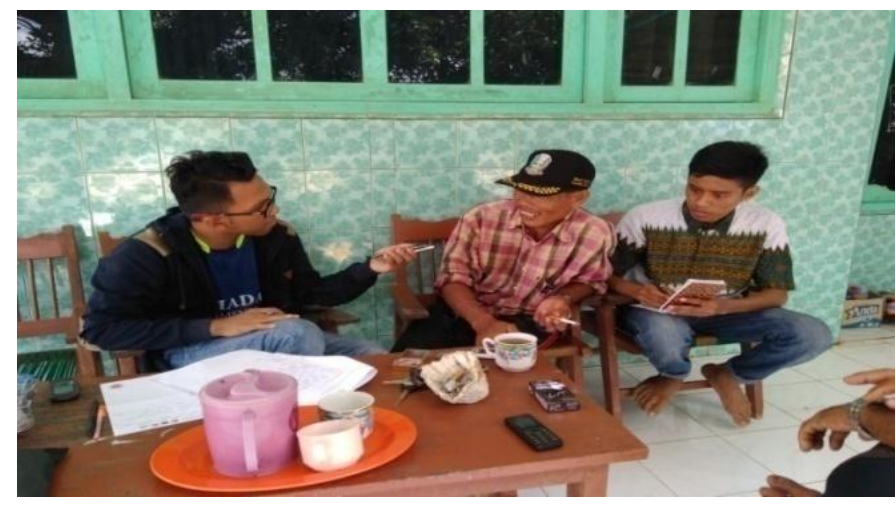

Gambar 2. Melakukan Wawancara (Sumber: Dokumentasi pribadi) 
Jurnal Pendidikan Geografi:

Kajian, Teori, dan Praktik dalam Bidang Pendidikan dan Ilmu Geografi

Tahun 24, Nomor 1, Jan 2019, Hal 1-10

\section{Tradisi Lombe di Pulau Kangean}

Kebudayaan sebagai aktivitas manusia yang melibatkan unsur karsa, rasa dan ciptaibarat lingkaran yang tidak mengenal ujung ataupun pangkalnya. Menurut Van Peursen (1988:233) kebudayaan sebetulnya bukan suatu kata benda, melainkan suatu kata kerja atauperkataan dan perbuatan. Kebudayaan adalah karya kita sendiri, tanggung jawab kita sendiri. Demikian kebudayaan dilukiskan secara fungsionil, yaitu sebagai suatu relasi terhadap rencana hidup kita sendiri. Kebudayaan lalu nampak sebagai suatu proses belajar raksasa yang sedang dijalankan oleh umat manusia. Proses melestarikan kebudayaan itupada hakekatnya akan mengarah kepada perilaku kebudayaan dengan sendirinya, jika dilakukan secara terus menerus dan dalam kurun waktu tertentu.

Tradisi merupakan gambaran sikap dan perilaku manusia yang telah berproses dalam waktu lama dan dilaksanakan secara turun-temurun dari nenek moyang. Tradisi di pengaruhi oleh kecenderungan untuk berbuat sesuatu dan mengulang sesuatu sehingga menjadi kebiasaan.Tradisi Lombe sebagai salah satu kebudayaan Indonesia dari Pulau Kangean. Tradisi Lombe (Kerapan Kerbau) merupakan tradisi turun-temurun yang dilaksanakan masyarakatkangean mulai dari tahun 1960-an sampai sekarang. Dalam pelaksanaan tradisi ini Sepasang kerbau diadu kecepatannya dengan sepasang kerbau lainnya tanpa joki (tidak seperti kerapan sapi) dan pasangan kerbau itu digiring masing-masing oleh dua kuda yang dinaiki joki. Fungsi joki kuda untuk menggertak kerbau itu sambil memukul dari arah samping kanan kiri, agar pasangan kerbau melaju lebih cepat sampai finis.

Menurut Juhari (2016) tradisi di madura melibatkan nilai-nilai keluhuran seperti dalam Tradisi Lombe masyarakat setempat mempercayai, setiap kali seseorang dapat memukul kerbau yang sedang berlari, hanya untuk diniatkan untuk memukul dan mengusir roh halus yang disimbolkan sebagai roh jahat yang bergentayangan menyusup atau menyerupai binatang,karena didalam kerbau disimbolkan terdapat sejumlah penyakit dan marabahaya yang bisa mengganggu keselamatan dan ketentraman warga, khususnya dalam pertumbuhan hasil pertanian maka dalam pertunjukan ini, para pengunjung juga ikut berebut untuk memukul kerbau yang lari kencang di lapangantempat kerapan atau lomba itu berlangsung. Alat pukulnya menggunakan kayu dengan berbagai ukuran. Masyarakat kangean juga percaya bahwa dulu pada saat kemarau di Pulau Kangean dengan dilakukannya tradisi tersebut dapat memberikan berkah ditandai dengan turunnya hujan sehingga menyelamatkan pertanian "padi dan jagung" yang ada di Pulau Kangean.

Tradisi Lombe dilaksanakan pada hari minggu, biasanyadilakukan sesudah menanam padi sampai waktu panen tujuannya mengisi waktu sembari menunggu panen. Sehari Sebelum dilakukan Tradisi Lombe tepatnya hari sabtu (13.00 wib) dilakukanJejel menurut pemahaman masyarakat Pulau Kangean Jejel ini untuk uji coba atau latihan sebelum melakukan pertandingan yang sesungguhnya dengan tujuan agar mengetahui kondisi kerbau, serta kecepatan kerbau seperti apa. Sebelum masyarakat melakukan tradisi lombe biasanya malam hari sebelum pertandingan berlangsung dilakukan "tatangenan" yaitu kegiatan yang dilakukan oleh pemilik kerbau sebagai persiapan lombe. Kerbau harus diletakkan di "padeng-padeng" depan rumah. Pada saat malam "tatangenan" banyak Keluarga, kerabat dan tetangga yang berdatangan untuk melakukan ritual "mamaca" membaca kitab nurbuat dengan harapan agar sepasang kerbau yang di pertandingakan mendapatkan keselamatan, dijauhi dari marabahaya serta dengan harapan untuk mendapatkan kemenangan. Kerbau yang akan di pertandingkan dalam Tradisi Lombe harus dijaga semalam suntuk dengan tujuan agar kerbau terhindar dari guna-guna dan paginya dimandikan sebersih mungkin lalu di hias dengan peralatan/pakaian kerbau ketika bertanding: 1) Onongan; 2) Pangaler; 3) Jemang; 4) Salobung; 5) Sentang; 6) Cara-cara; 7) Kronong, supaya tidak malu saat memasuki arena pertandingan Lombe. 
Tradisi Lombe sudah puluhan lamanya berlangsung di Pulau Kangean dan Mulai tahun 2010 Tradisi Lombe mulai mengalami perubahan dan perkembangan dengan menyesuaikan zaman, lebih menjadi tradisi modern, sedangkan pada tahu 90-an masih tradisi lombe kuno dengan sistem kekalahan dan kemenangan tidak ada yang menentukan, sedangkan pada masa sekarang sudah ada finis dan start yang ditentukan oleh panitia dan kemenangan sudah ada yang menentukan. Dimulai tahun 2010 dalam satu tahun dilakukan dua kali pelaksanaan Tradisi Lombe, karena dipengaruhi oleh pelaksanan panen padi yang juga dua kali dalam satu tahun. Pada saat pertandingan Tradisi Lombe berlangsung diiringi oleh musik tradisional Kangean yang disebut "Gendeng Dumik" dalam gendeng dumik terdapat berbagai alat musik (dua buah gendang, satu sarone dan satu gung). Adanya gendeng dumik untuk menyemarakkan dan membuat pertandingan lebih menarik serta membuat masyarakat terhibur. Setelah Tradisi Lombe selesai para pemenang melakukan sesuatu yang unik yaitu dengan cara mengiringi kerbau dengan "Gendeng dumik" disertai pemilik dan masayarakat melakukan tarian "Negel" sampai ke halaman rumah pemilik kerbau tersebut sebagai gambaran bahwa mereka merasa bahagia dan bersukur atas kemenangannya.

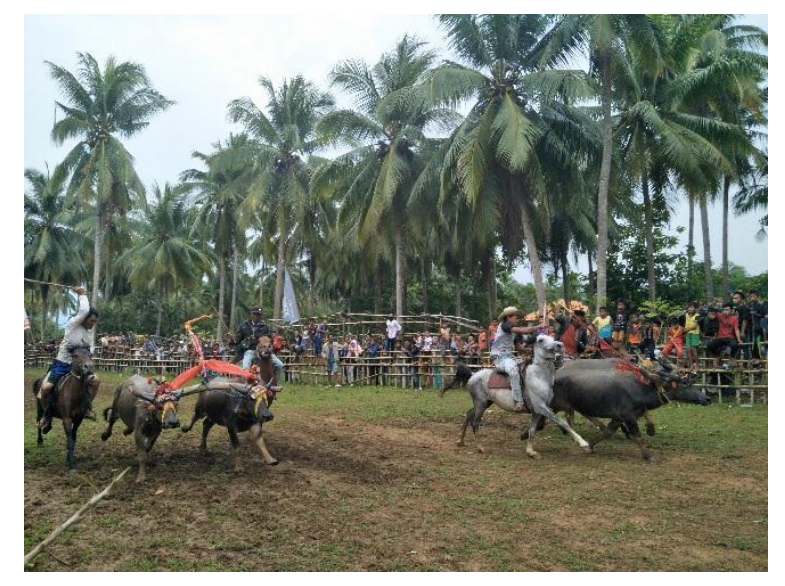

Gambar 3. Kegiatan Tradisi Lombe (Sumber: Dokumentasi pribadi)

\section{Konservasi Kerbau di Pulau Kangean}

Dolhalewan (2013) menyatakan bahwa pelestarian plasma nutfah dapat dilakukan dengan cara in-situ dan ex-situ. Definisi konservasi in-situ menurut FAO, (2000) adalah gabungan semua kegiatan yang bertujuan untuk mempertahankan populasi ternak hidup, termasuk ternak yang berada dalam program pemulian yang sedang berjalan aktif pada agroekosistem dimana mereka berkembang atau secara normal dijumpai, bersama-sama dengan aktivitas beternak yang ditujukan untuk secara berkelanjutan sumberdaya genetik ternak ini memberikan sumbangan terhadap produksi pangan dan pertanian untuk waktu sekarang dan yang akan datang. Konservasi ex-situ merupakan metode konservasi yang menangkarkan spesies di luar distribusi alami dari populasi tetuanya. Program global untuk strategi konservasi ex-situ sedang dikembangkan, khususnya dalam penggunaan populasi ternak hidup dalam mendukung pengembangan teknologi kriopreservasi. Pelestarian kerbau di Pulau Kangean termasuk ke dalam cara konservasi in-situ karena masih berkembang secara normal dan sederhana tidak menggunakan teknolgi tetapi menggunakan cara tradisional salah satunya Tradisi Lombe.

Konservasi insitu akan didukung atau sebaliknya oleh kebiasaan masyarakat. Kebiasaan masyarakat kangean yang saat ini sudah jarang menggunakan kerbau untuk 
Jurnal Pendidikan Geografi:

Kajian, Teori, dan Praktik dalam Bidang Pendidikan dan Ilmu Geografi

Tahun 24, Nomor 1, Jan 2019, Hal 1-10

membajak sawah dan kebiasaan masyarakat kangean dan Jawa Timur pada umumnya tidak mengkonsumsi daging kerbau yang menjadi ancaman terhadap keberadaan kerbau. Hal ini akan mempengaruhi minat masyrakat dalam melihara kerbau yang akan berujung pada kepunahan jika kerbau tidak lagi dibutuhkan atau tidak ada kegunaannya di pulau kangean.Tradisi Lombe menjadi perencanaan konservasi kerbau merupakan langkahyang tepat untuk tetap mempertahankan dan memperhatikan perkembangan kerbau di Pulau Kangean. Pelaksanaan Tradisi Lombe yang menjadi objek utama adalah kerbau. Masyarakat kangean dulu banyak yang memelihara kerbau untuk digunakan petani membajak sawah tetapi semakin berkembangnya teknologi hal tersebut mulai ditinggalkan. Pada perkembangannya masyarakat kangean juga memelihara kerbau untuk berpartisipasi dalam pelasksanaan Tradisi Lombe. Menurut narasumber bapak Gassing Tradisi Lombe dapat meningkatkan minat masyarakat dalam memelihara kerbau.

Tahun 2010 Tradisi Lombe menjadi tradisi yang berkembang sangat baik dan menjadi tradisi yang banyak diminati masyarakat kangean seiring dengan hal tersebut kondisi perkembangan perternakan kerbau di Pulau Kangean setiap tahunnya konstan tidak pernah turun. Dibuktikan dengan data resmi dari Dinas Perternakan Kabupaten Sumenep pada tahun 2012 jumlah ternak kerbau 5.027, tahun 2014 berjumlah 5.039 kerbau, dan pada tahun 2016 menjadi 5.051 kerbau. Dengan adanya Tradisi Lombe ini masyarakat sangat antusias dalam memelihara kerbau dan masyarakat kangean sudah mulai secara intensif dalam memelihara kerbau (merawat dengan sungguh-sungguh) supaya tidak malu ketika dibawa kepertandiangan "Tradisi Lombe". Dalam memelihara kerbau masyarakat memberikan pakan ternak dengan rumput, jerami, dedak padi secara rutin serta minum jamu dengan ramuan tradisional jamu tersebut campuran dari beberapa bahan seperti telur, beras kencur, kunyit dan rempah lainnya serta melatih kerbau untuk berlari sehingga menjadi kerbau dengan kualitas yang tinggi. Pada saat mengikuti dan memenangkan pertandingan secara terus menerus dalam Tradisi Lombe nilai harga jual kerbau semakin tinggi, dilihat juga dari kualitas dan bobot kerbau dengan kecepatan lari yang tinggi. Tradisi Lombe berpengaruh terhadap harga nilai jual kerbau di Pulau kangean. Hal ini yang menjadi salah satu alasan masyarakat memelihara kerbau, karena kerbau juga sebagai salah satu investasi masyarakat kangean. Tetapi, keuntungan ekonomi dari konservasi sulit untuk diketahui, karena perubahan untuk masa mendatang tidak dapat diprediksi (Subandriyo2010).

Kondisi perternakan kerbau di Pulau Kangean berkembang dengan baik, diikuti dengan Tradisi Lombe yang saat ini menjadi tradisi yang lebih modern dan diterima disetiap kalangan masyarakat. Pulau Kangean sebagai salah satu pulau di Madura yang mengirim kerbau keluar daerah seperti ke Kalimantan Selatan, Jawa Tengah, Banten dan Jawa Barat untuk memenuhi kebutuhan daging masyarakat Indonesia. Peranan ternak kerbau cukup signifikan dalam menunjang program swasembada daging kerbau tahun 2014, dilihat dari jumlah populasi kerbau sebanyak 2,2 juta ekor di Indonesia dan dihasilkan produksi daging sebesar 46 ribu ton atau sebesar $2 \%$ dari jumlah produksi daging nasional, sedangkan kontribusi daging kerbau sebesar 19\% (DITJENNAK 2012). Kerbau yang di kirim ke luar daerah merupakan kerbau jantan, sedangkan kerbau betina tetap di Pulau Kangean kecuali (kerbau betina yang sudah tidak produktif lagi atau tidak bisa beternak) hal ini sebagai salah satu bentuk Konservasi sehingga keberadaan kerbau di Pulau Kangean tetap terjaga

Data resmidari Dinas Perternakan Kabupaten Sumenep tahun 2016 memaparkan, pengiriman kerbau kangean ke luar pulau mengalami peningkatan yang cukup signifikan setiap tahunnya mulai dari tahun 2012 sejumlah 485 kerbau, pada tahun 2013 naik 150 kerbau menjadi 635 kerbau yang dikirim, selanjutnya tahun 2014 meningkat menjadi 890 kerbau dengan peningkatan jumlah 255 kerbau, tetapi pada tahun 2015 pengiriman jumlah kerbau menjadi 885 kerbau dan pada tahun 2016 meningkat lagi menjadi 975 kerbau. Dari 
Jurnal Pendidikan Geografi:

Kajian, Teori, dan Praktik dalam Bidang Pendidikan dan Ilmu Geografi

Tahun 24, Nomor 1, Jan 2019, Hal 1-10

data yang disajikan Hal ini menunjukkan Penerapan Tradisi Lombe sebagai salah satu upaya konservasi kerbau di Pulau Kangean menjadi salah satu faktor Pulau Kangean menjadi salah satu pemasok kebutuhan kerbau di berbagai daerah di Indonesia.

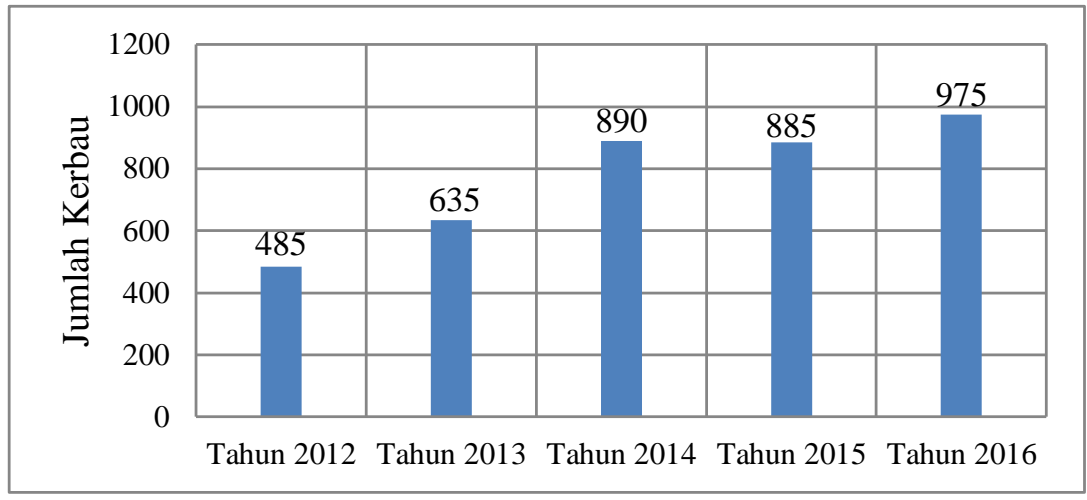

Gambar 4. Grafik Jumlah Pengiriman Kerbau di Pulau Kangean Kabupaten Sumenep (Sumber : Dinas Perternakan Kabupaten Sumenep)

\section{Dampak Tradisi Lombe terhadap Sosial Ekonomi Masyarakat Pulau Kangean}

Tradisi Lombe yang diadakan sejak turun-temurun diharapkan dapat memperbaiki kehidupan sosial ekonomi masyarakat Pulau Kangean. Tradisi Lombe dilakukan untuk meneruskan kebiasaan atau tradisi para sesepuhsebagai hiburan dan ritual bagi masyarakat yang menanam padi. Tradisi Lombe meningkatkan harga nilai jual kerbau yang juga dilihat dari kualitas kerbau dengan kecepatan lari yang tinggi. Kerbau yang sering memenangkan lombe tersebut akan berdampak pada bibitnya yang dipercaya oleh masyarakat kangean akan menghasilkan bibit unggul. Jadi, keturunan dari kerbau yang memenangkan tradisi ini harga jualnya lebih mahal daripada kerbau yang biasa.Hal ini Bagi pelaku Tradisi Lombe upaya untuk menjamin sumber ekonomi dan devisa Negara (Darmanto 2011). Masyrakat Kangean dapat membuka usaha baru seperti berjualan makanan, minuman, jasa parkir dan lain-lain di arena Lombe. Terbuka pula peluang jasa membuat peralatan atau perlengkapan Lombe, serta penyedia musik pengiring.

Tradisi ini tidak hanya berdampak terhadap ekonomi mayarakat tetapi dibalik hal tersebut ajang ini menjadi tempat berkumpulnya maupaun bertemunya masyarakat kangean untuk saling berinteraksi yang dapat mempererat tali silaturrahim, menumbuhkan solidaritas, rasa persaudaraan dan memperkuat ikatan sosial masyarakat Kangean. Menurut narasumber bapak Muksin (umur 86 tahun) bahwa dulu saat tahun 1960-an saya tidak banyak mengenal masyarakat kangean antar desa, tetapi setalah ikut berpartisipasi dalam tradisi ini, saya banyak mengenal mereka dan sampai sekarang tetap bersilaturrahim. 
Jurnal Pendidikan Geografi:

Kajian, Teori, dan Praktik dalam Bidang Pendidikan dan Ilmu Geografi

Tahun 24, Nomor 1, Jan 2019, Hal 1-10

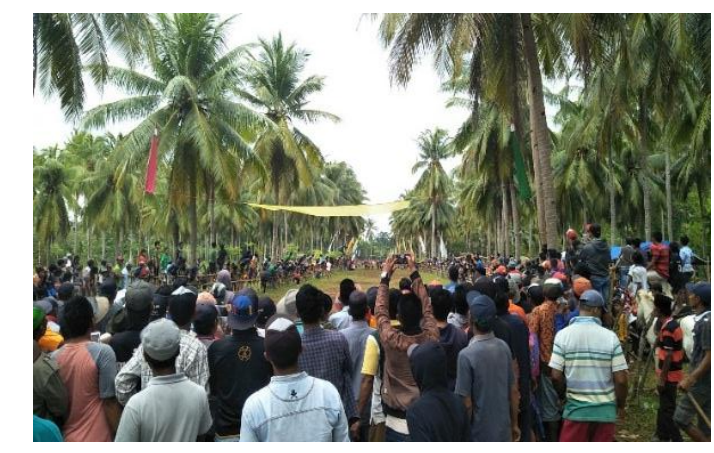

Gambar 5. Kondisi Sosial masyarakat Kangean (Sumber: Dokumentasi pribadi)

\section{KESIMPULAN}

Tradisi Lombe merupakan tradisi kerapan kerbau yang dilakukan secara turuntemurun yang dilaksanakan masyarakat Pulau Kangean sejak tahun 1960-an. Dalam Lombe, sepasang kerbau diadu kecepatannya dengan sepasang kerbau lainnya tanpa joki (tidak seperti kerapan sapi). Pasangan kerbau itu digiring masing-masing oleh dua kuda yang dinaiki joki. Tradisi Lombe pada dasarnya bukan sekedar suatu pertunjukan lomba atau kerapan semata, konon dibalik tradisi itu terdapat nilai ritual sebagai bentuk usaha masyarakat setempat memohon kepada Yang Maha Kuasa agar dilimpahkan rezeki ketika panen.

Tradisi Lombe juga dapat mempengaruhi minat masyarakat dalam memelihara kerbau sehingga Tradisi Lombe menjadi solusi dalam menjaga keberadaan kerbau di Pulau Kangean. Pelaksanaan Tradisi Lombe sebagai salah satu upaya konservasi kerbau menjadi salah satu faktor Pulau Kangean menjadi salah salau pemasok kebutuhan kerbau di berbagai daerah di Indonesia.

Tradisi Lombe sebagai ajang silaturrahmi dan mempererat rasa persaudaraan masyarakat dan dapat meningkatkan harga jual kerbau, membuka peluang usaha bagi masyarakat sehingga dapat meningkatkan kesejahteraan masyarakat.Pemerintah Kabupaten Sumenep dapat menjadikan penelitian ini untuk refrensi pengembangan Tradisi Lombe sebagai ikon budaya Kabupaten Sumenep secara khusus dan Indonesia secara umum. Pelestarian Tradisi ini juga dapat menjaga keberadaan kerbau di Pulau Kangean.

\section{DAFTAR RUJUKAN}

BPS Kabupaten Sumenep. (2014). Kabupaten Sumenep dalam angka 2014. Retrieved from http://sumenepkab.bps.go.id/index.php?hal= publikasi_detil\&id=47.

Darmanto. (2011). Konversi global, taman nasional dan praktek lokal di Pulau Simberut, Sumatera Barat. UNESCO. 5 (2): 52.

Dinas Perternakan Kab Sumenep. (2016). Dinas Kabupaten dalam angka 2016. Retrieved from:http://dinasperternakankabupatensumenep.go.id/index.php?hal=publikasi_de tik'\&id=49

Djojoprajitno, Sahwanoedin. (2005). Kangean dari zaman wilwatikta sampai Republik Indonesia (1350-1950). Buletin Kangean Nyiur Melambai (KNM).

DITJENNAK. (2012). Pedoman teknis pengembangan perbibitan kerbau tahun 2012. Jakarta: Direktorat Jenderal Peternakan Deptan RI.

DITJENNAK. (2006). Buku statistik peternakan Direktorat Produksi Peternakan. Jakarta: Direktorat Jenderal Peternakan Deptan. RI. 
Jurnal Pendidikan Geografi:

Kajian, Teori, dan Praktik dalam Bidang Pendidikan dan Ilmu Geografi

Tahun 24, Nomor 1, Jan 2019, Hal 1-10

Dolhalewan, dkk. (2013). Pola konservasi kerbau moa dan alternatif konservasinya di Pulau Moa Kabupaten Maluku Barat Daya. Agrinimal. 3(2):72.

FAO. (2000). The state of world fisheries and aquaculture. Roma: Food and Agricultural Organization.

Juhari. (2016). Ekonomi dan prestise dalam budaya kerapan sapi di Madura. Jurnal sosial dan budaya keislaman IAIN jember. 24 (2): 186-204

Miles, M. \& Huberman, A.M. (2010). Analisis data kualitatif: buku sumber tantang metodemetode baru. Jakarta: UI Press.

Subandriyo. (2010). Konservasi sumberdaya genetik ternak: pertimbangan, kriteria, metode, dan strategi. Lokarya Nasioanal Pengelolaan dan Perlindungan Sumber Daya.

Ulum, M, Hardiyati, K. \& Irfan. (2017). Pengembangan sumber daya manusia melalui tradisi lombe di Pulau Kangean. Paper presented at Seminar Nasional Geografi UMS, 23 Mei 2017 (pp. 750-760).

Van, P. (1998). Strategi kebudayaan. Yogyakarta: Kanisius.

Warner, M. \& Joynt, P. (2002). Introduction: cross-cultural perspectives. Managing Across Cultures: Issues and Perspective. London: Thomson Learning. 